\title{
ANALISIS TECHNOLOGICAL PEDAGOGICAL AND CONTENT KNOWLEDGE (TPACK) GURU GEOGRAFI DI KABUPATEN SOLOK, SUMATERA BARAT
}

\author{
Nofrion1, Bayu Wijayanto1, Ratna Wilis', Rery Novio' \\ 1Universitas Negeri Padang \\ Jalan Prof. Dr. Hamka, Air Tawar Padang, Sumatera Barat \\ Email: nofrion@fis.unp.ac.id
}

\begin{abstract}
Abstrak
Artikel ini ditulis untuk mengetahui dan menganalisis kompetensi TPACK Guru Geografi di Kabupaten Solok. Data dalam artikel ini didapatkan dari penelitian yang melibatkan 16 orang Guru yang terdiri dari data kompetensi TPACK guru dalam hal penguasaan materi, pemanfaatan media dan teknologi dalam pembelajaran serta kompotensi pedagogik yang dilihat dari dokumen perencanaan pembelajaran/RPP dan kinerja dalam pelaksanaan pembelajaran. Data didapatkan dengan Paket Soal Tes Penguasaan Materi yang valid, Lembar Observasi Pemanfaatan Media dan Teknologi dalam Pembelajaran, Lembar Observasi Pembelajaran serta Lembar Check List untuk analisis Dokumen. Data dianalisis dengan deskriptif kuantitatif. Hasil penelitian menunjukkan bahwa TPACK - Content Knowledge Guru Geografi di Kabupaten Solok berada pada kategori sedang atau pada nilai rata-rata 51. Soal materi kelas $X$ adalah soal paling sulit bagi guru. Hasil TPACK - Technology guru Geografi menunjukkan kategori sedang. Namun, terindikasi media presentasi yang ditampilkan adalah hasil modifikasi dari media yang sudah dibuat orang lain. Sedangkan TPACK - Pedagogic Guru berdasarkan kinerja dalam pelaksanaan pembelajaran memiliki rata-rata 80,79 atau berada pada kategori sedang dengan tingkat relevansi komponen RPP dengan Standar Proses adalah $100 \%$. Berdasarkan data di atas maka perlu diberikan pembinaan untuk meningkatkan penguasaan materi kelas X bagi guru. Lalu, pelatihan untuk merancang media presentasi pembelajaran berbasis Ms. Office Power Point dan lain-lain hasil karya sendiri serta penguatan dalam merancang RPP berdasarkan karakteristik siswa di sekolah masing-masing.
\end{abstract}

Kata Kunci: Kompetensi TPACK, Pembelajaran Geografi

\begin{abstract}
This article was written to find out and analyze Geography Teacher's TPACK competence in Solok Regency. The data in this article was obtained from a study involving 16 teachers consisting of teachers' TPACK competency data in terms of materials mastery, media and technology utilization in learning and also pedagogical competence which is seen from lesson plan/RPP and performance in learning implementation. Data were obtained with valid Material Mastery Test Package, Observation Sheet of Media and Technology Utilization in Learning, Learning Observation Sheet and Checklist Sheet for Document analysis. Data were analyzed by quantitative descriptive. The results showed that TPACK - Content Knowledge of Geography Teachers in Solok Regency was in the medium category or in the average score of 51. The question of class X materials is the most difficult thing for teachers. The result
\end{abstract}


of TPACK - Technology of Geography teacher shows medium category. However, it is indicated that media presentation which is displayed is the result of modifications from the media that has been created by others. Moreover, TPACK - Pedagogic of teacher based on performance in learning implementation have average 80,79 or in medium category, with RPP component relevance level with Standard Process is $100 \%$. Based on the data above, it is necessary to provide coaching to improve mastery of class $X$ materials for teachers. In addition, the training to design their own instructional media presentation based on Ms. Office Power Point etc. and also strengthening in designing RPP based on the characteristics of students in each school.

Keywords: Geography Learning, Geography Teacher, TPACK Competency

\section{PENDAHULUAN}

Abad 21 ditandai dengan perubahan luar biasa dalam berbagai sisi kehidupan manusia. Alfin Toffler menyebutnya dengan masyakat gelombang ketiga (the third wave society) dan John Naisbit menyatakan dengan istilah masyarakat informasi (information society). Perubahan dunia yang demikian cepat harus diiringi oleh praktik pendidikan yang relevan dengan tuntutan perubahan tersebut. Pada tahun 2009, sebuah laporan dengan judul "Learning for the 21st Century" mempublikasikan "Framework for 21st Century Learning" yang menjelaskan tentang empat kompotensi atau bidang yang harus dikuasai oleh peserta didik yang meliputi "1) core subject and 21st century themes, 2) learning and innovative skills, 3) information, media and technology skills and 4) life and career skills" (Marzano \& Heflebower, 2012:3). Empat kompetensi yang disebut sebagai kerangka pembelajaran abad 21 merupakan upaya untuk menyelaraskan praktik pendidikan dengan tuntutan zaman.

Sejalan dengan hal tersebut, Pemerintah Republik Indonesia melalui Kementerian Pendidikan dan Kebudayaan/Kemdikbud RI telah menetapkan Permendikbud nomor 23 tahun 2015 tentang Penumbuhan Budi Pekerti yang menjadi dasar dari Gerakan Literasi Sekolah. Gerakan Literasi Sekolah meliputi lima aspek yaitu "1) basic literacy,
2) library literacy, 3) media literacy, 4) technology literacy and 5) visual literacy". Terkait dengan pembelajaran berdasarkan Kurikulum 2013, dalam Permendikbud nomor 22 tentang Standar Proses dijelaskan bahwa ada dua prinsip pembelajaran dalam Kurikulum 2013 yang relevan dengan perkembangan global yaitu pemanfaatan teknologi informasi dan komunikasi untuk meningkatkan efisiensi dan efektivitas pembelajaran dan penyediaan berbagai sumber belajar dan media pembelajaran terutama media dan sumber belajar berbasis ICT/Multimedia. Dari uraian di atas terlihat bahwa regulasi pelaksanaan pembelajaran di Indonesia sudah mengikuti perkembangan yang ada di dunia.

Namun, permasalahannya adalah sekolah dan guru di Indonesia masih dililit oleh berbagai masalah akut diantaranya masalah standar guru, penguasaan materi dan rendahnya penguasaan media dan teknologi/literacy media and technology. Tidak ada perbedaan kualitas pendidikan Indonesia sebelum dan sesudah sertifikasi guru dilaksanakan. Bahkan, Bank Dunia menegaskan bahwa sertifikasi guru tidak memperlihatkan dampak yang nyata terhadap hasil pendidikan walaupun sudah menghabiskan dana yang cukup banyak.Ditambah lagi dengan hasil Uji Kompetensi Guru tahun 2012 yang dirilis oleh Kemendikbud RI memperlihatkan 
bahwa kemampuan rata-rata guru di Indonesia baru mencapai angka 44 dari skala $\quad 100 \quad$ (http://ukg. kemendikbud.go.id).

Hal ini tentu menjadi tantangan berat bagi dunia pendidikan Indonesia. Apalagi dalam konteks global juga berkembang suatu bentuk pola pengembangkan kompetensi guru yang disebut dengan "TPACK" atau Technological, Pedagogical, Content Knowledge yang intinya, seorang guru harus memiliki pengetahuan dan keterampilan yang komprehensif dan holistik dalam hal konten/materi, pedagogik/ilmu mendidik serta teknologi (www.tpack.org diakses 10 April 2017). TPACK dicetuskan pertama kali oleh Shulman $(1987,1986)$ lalu dilanjutkan oleh Koehler \& Mishra (2008).

Peneliti di berbagai negara telah mempublikasikan hasil riset mereka terkait dengan "TPACK" sebagai salah satu upaya untuk mengembangkan kompetensi guru. Seperti penelitian Baran. E, Chuang, H.H, dan Thompson, A (2011) yang berjudul "TPACK: An Emerging Research And Development Tool For Teacher Educators". Hasilnya adalah TPACK menjadi alat dan cara yang efektif untuk menggali kemampuan guru dalam hal penguasaan teknologi dan kemampuan mereka dalam menggunakan teknologi dalam pembelajaran. Demikian juga dengan penelitian Ersan (2016) yang berjudul "Improving Technological Pedagogical Content Knowledge (TPACK) of Pre-Service English Languange Teachers". Penelitian yang dipublikasikan dalam Journal of International Educational Studies, Canadian Center of Science and Education, ini mengungkapkan bahwamelalui suatu pelatihan/workshop aspek-aspek "TPACK" kepada mahasiswa dapat meningkatkan skor aspek-aspek "TPACK" mahasiswa secara signifikan. Dari dua contoh hasil penelitian ini dapat diketahui bahwa penelitian "TPACK" dalam berbagai topik dapat meningkatkan kualitas guru maupun mahasiswa dalam hal penguasaan konten, pedagogi dan teknologi.

TPACK (Technological, Pedagogical, Content Knowledge) dicetuskan pertama kali oleh Shulman (1987) tentang PCK yang menjelaskan mengenai pemahaman guru tentang teknologi pendidikan dan interaksi PCK satu dengan yang lain untuk menciptakan pembelajaran yang efektif menggunakan teknologi. Dalam model ini, terdapat tiga komponen utama mengenai pengetahuan guru: konten, pedagogi, dan teknologi. Konsepsi TPACK dijelaskan di sini telah berkembang dari waktu ke waktu dan melalui serangkaian publikasi, dengan deskripsi paling lengkap dari kerangka yang ditemukan di Mishra \& Koehler (2006) dan publikasi berikutnya oleh Koehler \& Mishra (2008:62).

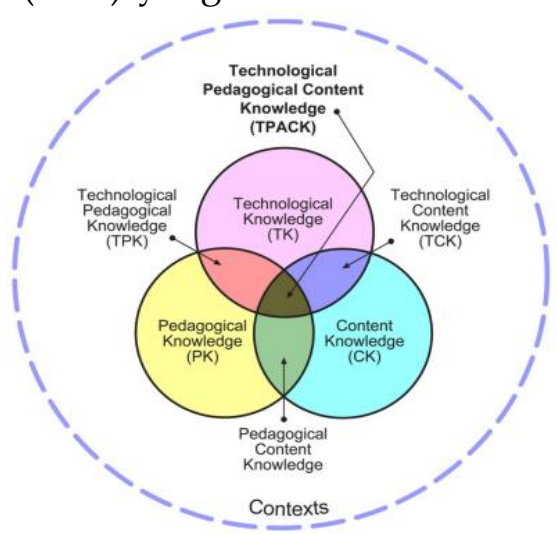

Gambar 1 : Komponen TPACK

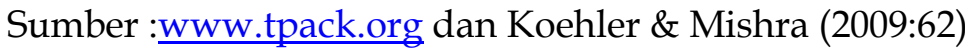


Secara umum, komponen TPACK dijelaskan dalam situs resmi TPACK yaitu www.tpack.org serta dirilis juga oleh Koehler \& Mishra (2008:62). Technology, Pedagogy, and Content Knowledge (TPACK). TPACK adalah bentuk pengetahuan yang meliputi tiga komponen utama yaitu konten, pedagogi, dan teknologi. Pengetahuan teknologi konten pedagogis adalah pemahaman yang muncul dari interaksi antara konten, pedagogi, dan teknologi pengetahuan. TPACK adalah dasar pengajaran yang benar-benar bermakna dan sangat terampil dengan teknologi, ini berbeda dari pengetahuan tentang tiga konsep secara individual. Sebaliknya, TPACK adalah dasar dari mengajar yang efektif dengan teknologi, memerlukan pemahaman tentang representasi dari konsep-konsep yang menggunakan teknologi; teknik pedagogis yang menggunakan teknologi dalam cara yang konstruktif untuk mengajarkan materi/konten; pengetahuan tentang apa yang membuat konsepkonsep sulit atau mudah untuk belajar dan bagaimana teknologi dapat membantu memperbaiki beberapa masalah yang dihadapi siswa; pengetahuan siswa dan teori-teori Epistemologi; dan pengetahuan tentang bagaimana teknologi dapat digunakan untuk membangun pengetahuan untuk mengembangkan metode/cara-cara baru atau memperkuat yang lama.

Guru profesional harus memiliki kompetensi TPACK yang memadai karena TPACK berada dalam ranah empat kompetensi utama seorang guru yang meliputi kompetensi pedagogik, kompetensi kepribadian, kompetensi sosial, dan kompetensi profesional yang diperoleh melalui pendidikan profesi (UU Nomor 14 tahun 2005 Pasal 10). Apalagi jika dikaitkan dengan tren pendidikan global seperti "Framework $21^{\text {st }}$ century learning", lalu pengintegrasian " $4 C$ " dalam pembelajaran yaitu Communication, Collaboration, Creativity dan Critical Thinking. Marzano \& Heflebower (2012:34) dalam bukunya yang berjudul "Teaching \& Assessing 21st Century Skills" menjelaskan bahwa ada empat aspek atau bidang yang harus dimiliki oleh seorang lulusan sekolah, yaitu: 1) Subjek dan tema inti, 2) Keterampilan pembelajaran dan inovasi, 3) Keterampilan informasi, media dan teknologi, 4) Kecakapan hidup dan karier. Tentunya, hal tersebut harus dimulai dari sisi guru sebagai fasilitator pembelajaran.

Oleh sebab itu, pola pengembangan kompetensi guru dengan istilah "TPACK" merupakan sebuah jalan cerdas untuk menjamin terlaksananya pembelajaran sesuai dengan tuntutan dan perubahan yang terjadi. Sebelum melakukan program-program pemberdayaan dan pengembangan kompetensi guru, maka diperlukan sebuah penelitian untuk mengetahui dan menganalisis kondisi "TPACK" guru yang akan menjadi landasan perumusan kebijakan selanjutnya.

\section{METODE PENELITIAN}

Jenis penelitian adalah deskriptif dengan pendekatan kuantitatif.Penelitian ini dilaksanakan di Kabupaten Solok, Sumatera Barat yang terletak sekitar 70 km dari Kota Padang. Populasi penelitian adalah guru Geografi SMA/MA yang ada di Kabupaten Solok serta aktif dalam kegiatan MGMP. Dalam penelitian ini, untuk sampel TPACK -Content Knowledge adalah sebanyak 16 orang. Sedangkan sampel untuk TPACK - Technology adalah empat orang, demikian juga dengan sampel untuk TPACK - Pedagogic. Dalam analisis nantinya, responden dikelompokkan menjadi dua kelompok yaitu kelompok guru dengan pengalaman mengajar kurang dari 10 tahun dan guru 
dengan pengalaman mengajar lebih dari 10 tahun.

Teknik dan alat yang digunakan dalam mengumpulkan data penelitian adalah angket/kuisioner dan lembar observasi pembelajaran. Angket/kuisioner yang digunakan adalah hasil rancangan peneliti sendiri yang dikembangkan berdasarkan teori/konsep "TPACK" seperti yang terdapat di dalam kajian kepustakaan serta mempelajari hasil-hasil penelitian terkait. Dengan rincian:

1. Data TPACK - Content Knowledge didapatkan dengan tes tingkat penguasaan materi mata pelajaran Geografi yang telah melewati analisis butir soal dengan aplikasi Anatest setelah dilakukan uji coba soal. Hasil tes akan dikelompokkan menjadi tiga kategori yaitu Tinggi, Sedang dan Rendah.

2. Data TPACK - Technology didapatkan dengan lembar observasi pembelajaran yang difokuskan pada penggunaan media presentasi pembelajaran yang digunakan guru di dalam kelas.

3. Data TPACK - Pedagogic didapatkan melalui analisis dokumen RPP dan mengobservasi pelaksanaan pembelajaran dengan menggunakan satu lembar observasi standar Kurikulum 2013 (dikeluarkan oleh Kemendikbud RI untuk Peer Teaching PPG SM3T tahun 2017).

Data penelitian yang didapatkan selanjutnya dianalisis dengan analisis statistik desktiptif dan analisis dokumen.

\section{HASIL DAN PEMBAHASAN}

Penelitian ini diawali dengan kunjungan ke MGMP Geografi SMA/MA di Koto Baru, Kabupaten Solok dalam rangka sosialisasi rancangan dan tahapan penelitian yang akan dilakukan. Kegiatan berikutnya adalah melakukan penelitian untuk mengetahui kompetensi TPACK Content Knowledge atau tingkat penguasaan materi mata pelajaran Geografi oleh Guru Geografi SMA/MA di Kabupaten Solok. Bentuk kegiatan ini adalahguru diberikan satu paket soal yang berisi soal-soal yang disusun sesuai Permendikbud Nomor 24 tahun 2016 tentang Sebarab Kompetensi Dasar Mata Pelajaran Geografi sesuai Kurikulum 2013. Paket soal yang diujikan telah melalui proses ujicoba soal yang dilaksanakan pada MGMP Geografi SMA/MA Kota Padang. Hasil uji coba paket soal ini lalu dianalisis dengan anatest. Hasil analisis butir soal dengan aplikasi Anates memperlihatkan bahwa dari 70 soal yang diujicobakan, terdapat soal yang valid yaitu 50 butir. Soal inilah yang dijadikan sebagai soal tes penguasaan materi mata pelajaran Geografi kepada responden penelitian yaitu guru Geografi SMA/MA di Kabupaten Soal.

Hasil tes penguasaan materi mata pelajaran Geografi/TPACK - Content Knowledge MGMP Geografi SMA/MA Kabupaten Solok sebagai berikut:

a. TPACK - Content Knowledge untuk Materi Kelas X

Tabel 1. Nilai TPACK - Content Knowledge Materi Kelas X

\begin{tabular}{llllll}
\hline No & Responden & Asal Sekolah & Skor & Nilai & Kriteria \\
\hline 1 & ANL & SMAN 2 Singkarak & 10 & 56 & Sedang \\
2 & IMS & SMAN 2 Danau Kembar & 7 & 39 & Rendah \\
3 & EC & SMAN 1 Kubung & 12 & 67 & Sedang \\
4 & SL & SMAN 1 Singkarak & 12 & 67 & Sedang \\
5 & RD & SMAN 2 Gunung Talang & 9 & 50 & Sedang
\end{tabular}




\begin{tabular}{llllll}
\hline No & Responden & Asal Sekolah & Skor & Nilai & Kriteria \\
\hline 6 & MP & SMAN 1 Danau Kembar & 9 & 50 & Sedang \\
7 & RA & SMAN 1 Kubung & 9 & 50 & Sedang \\
8 & YA & SMAN 1 Danau Kembar & 9 & 50 & Sedang \\
9 & RH & SMAN 2 Lembang Jaya & 7 & 39 & Rendah \\
10 & BS & SMAN 2 Hiliran Gumanti & 6 & 33 & Rendah \\
11 & FS & SMAN 2 Hiliran Gumanti & 11 & 61 & Sedang \\
12 & YM & SMAN 1 Junjung Sirih & 6 & 33 & Rendah \\
13 & ESD & SMAN 2 SUMBAR & 10 & 56 & Sedang \\
14 & MH & SMAN I IX Koto Sungai Lasi & 11 & 61 & Sedang \\
15 & ZI & SMAN 1 IX Koto Sungai Lasi & 8 & 44 & Sedang \\
16 & AR & SMAN 1 Singkarak & 8 & 44 & Sedang \\
\hline
\end{tabular}

Sumber : Pengolahan Data Penelitian, 2017

Tabel di atas menunjukkan bahwa tingkat penguasaan guru terhadap materi Geografi kelas X sebagian besar berada pada level sedang. Malah empat diantara responden berada pada level rendah.
Tidak satupun responden yang mampu mencapai level tinggi.

a. TPACK - Content Knowledge untuk Materi Kelas XI

Tabel 2. Nilai TPACK - Content Knowledge Materi Geografi Kelas XI

\begin{tabular}{llllll} 
No & Responden & Asal Sekolah & Skor & Nilai & Kriteria \\
\hline 1 & ANL & SMAN 2 Singkarak & 9 & 47 & Sedang \\
2 & IMS & SMAN 2 Danau Kembar & 10 & 53 & Sedang \\
3 & EC & SMAN 1 Kubung & 15 & 79 & Tinggi \\
4 & SL & SMAN 1 Singkarak & 17 & 89 & Tinggi \\
5 & RD & SMAN 2 Gunung Talang & 11 & 58 & Sedang \\
6 & MP & SMAN 1 Danau Kembar & 7 & 37 & Rendah \\
7 & RA & SMAN 1 Kubung & 9 & 47 & Sedang \\
8 & YA & SMAN 1 Danau Kembar & 9 & 47 & Sedang \\
9 & RH & SMAN 2 Lembang Jaya & 11 & 58 & Sedang \\
10 & BS & SMAN 2 Hiliran Gumanti & 11 & 58 & Sedang \\
11 & FS & SMAN 2 Hiliran Gumanti & 10 & 53 & Sedang \\
12 & YM & SMAN 1 Junjung Sirih & 10 & 53 & Sedang \\
13 & ESD & SMAN 2 SUMBAR & 7 & 37 & Rendah \\
14 & MH & SMAN I IX Koto Sungai Lasi & 8 & 42 & Sedang \\
15 & ZI & SMAN 1 IX Koto Sungai Lasi & 7 & 37 & Rendah \\
16 & AR & SMAN 1 Singkarak & 6 & 32 & Rendah \\
\cline { 2 - 6 }
\end{tabular}

Sumber : Pengolahan Data Penelitian, 2017

Dari tabel terlihat bahwa empat responden berada pada level rendah, 10 responden masuk kelompok sedang dan ada dua responden meraih level tinggi. b. TPACK - Content Knowledge untuk Materi Kelas XII 
Tabel 3. Nilai TPACK - Content Knowledge Materi Geografi Kelas XII

\begin{tabular}{llllll}
\hline No & Responden & Asal Sekolah & Skor & Nilai & Kriteria \\
\hline 1 & ANL & Sman 2 Singkarak & 10 & 67 & Sedang \\
2 & IMS & Sman 2 Danau Kembar & 7 & 47 & Sedang \\
3 & EC & Sman 1 Kubung & 9 & 60 & Sedang \\
4 & SL & Sman 1 Singkarak & 13 & 87 & Tinggi \\
5 & RD & Sman 2 Gunung Talang & 7 & 47 & Sedang \\
6 & MP & Sman 1 Danau Kembar & 11 & 73 & Sedang \\
7 & RA & Sman 1 Kubung & 8 & 53 & Sedang \\
8 & YA & Sman 1 Danau Kembar & 6 & 40 & Sedang \\
9 & RH & Sman 2 Lembang Jaya & 6 & 40 & Sedang \\
10 & BS & Sman 2 Hiliran Gumanti & 5 & 33 & Rendah \\
11 & FS & Sman 2 Hiliran Gumanti & 8 & 53 & Sedang \\
12 & YM & Sman 1 Junjung Sirih & 9 & 60 & Sedang \\
13 & ESD & Sman 2 Sumbar & 7 & 47 & Sedang \\
14 & MH & Sman 1 IX Koto Sungai Lasi & 7 & 47 & Sedang \\
15 & ZI & Sman 1 Ix Koto Sungai Lasi & 5 & 33 & Rendah \\
16 & AR & Sman 1 Singkarak & 6 & 40 & Sedang \\
\hline
\end{tabular}

Sumber : Pengolahan Data Penelitian, 2017

Tabel di atas memperlihatkan bahwa penguasaan guru terhadap materi Geografi kelas XII secara umum berada pada kategori sedang. Hanya satu orang yang berhasil mencapai level tinggi dan ada dua responden masuk kelompok rendah.

d. TPACK - Content Knowledge Gabungan

Tabel 4. Kompetensi TPACK Guru Geografi SMA/MA di Kabupaten Solok

\begin{tabular}{llllll}
\hline No & Responden & Asal Sekolah & Skor & Nilai & Kriteria \\
\hline 1 & ANL & SMAN 2 Singkarak & 29 & 56 & Sedang \\
2 & IMS & SMAN 2 Danau Kembar & 24 & 46 & Sedang \\
3 & EC & SMAN 1 Kubung & 36 & 69 & Sedang \\
4 & SL & SMAN 1 Singkarak & 42 & 81 & Tinggi \\
5 & RD & SMAN 2 Gunung Talang & 27 & 52 & Sedang \\
6 & MP & SMAN 1 Danau Kembar & 27 & 52 & Sedang \\
7 & RA & SMAN 1 Kubung & 26 & 50 & Sedang \\
8 & YA & SMAN 1 Danau Kembar & 24 & 46 & Sedang \\
9 & RH & SMAN 2 Lembang Jaya & 24 & 46 & Sedang \\
10 & BS & SMAN 2 Hiliran Gumanti & 22 & 42 & Sedang \\
11 & FS & SMAN 2 Hiliran Gumanti & 29 & 56 & Sedang \\
12 & YM & SMAN 1 Junjung Sirih & 25 & 48 & Sedang \\
13 & ESD & SMAN 2 SUMBAR & 24 & 46 & Sedang \\
14 & MH & SMAN I IX Koto Sungai Lasi & 26 & 50 & Sedang \\
15 & ZI & SMAN 1 IX Koto Sungai Lasi & 20 & 38 & Rendah \\
16 & AR & SMAN 1 Singkarak & 20 & 38 & Rendah \\
\hline
\end{tabular}

Sumber : Pengolahan Data Penelitian, 2017 
Secara keseluruhan, tingkat penguasaan guru terhadap materi Geografi berada pada kategori sedang. Hanya satu responden yang bernilai

tinggi, namun ada dua yang bernilai rendah.Sebaran nilai TPACK Guru Geografi secara keseluruhan tergambar pada grafik berikut ini:

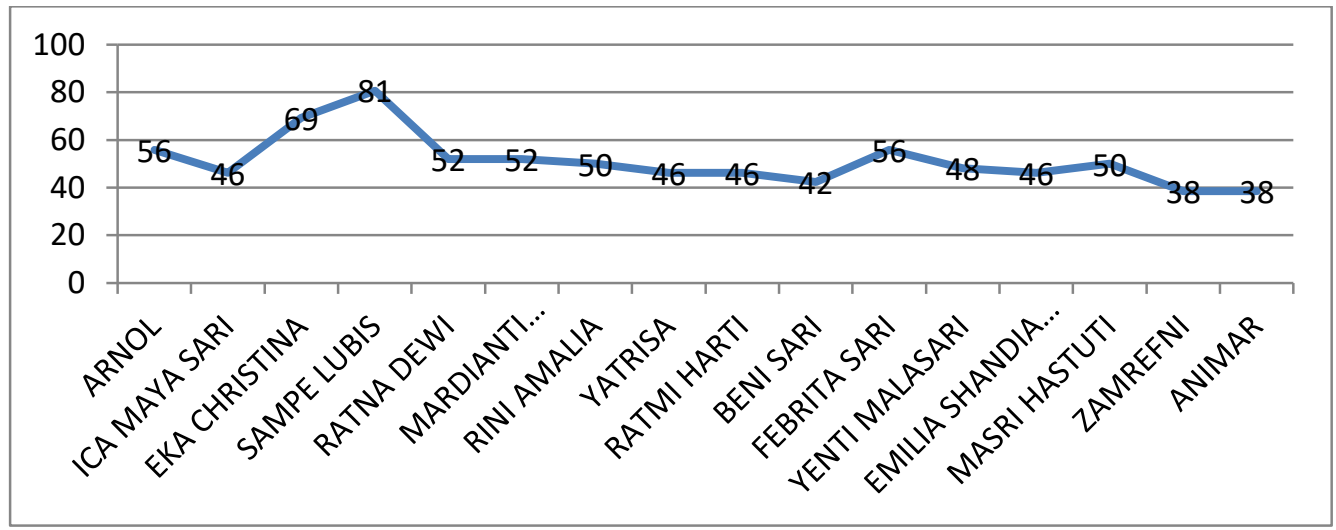

Gambar 2. Sebaran TPACK - Content Knowledge

Setelah mendapatkan data TPACK - Content Knowledge, lalu dilakukan penelitian untuk menggali kemampuan guru dalam hal TPACK - Technology yang secara spesifik diarahkan kepada kemampuan guru membuat dan menggunakan media dalam pembelajaran. Berdasarkan kondisi dan situasi yang ada diputuskan empat orang perwakilan guru sebagai sampel untuk TPACK - Technology dengan kriteria, dua orang guru yang sudah memiliki pengalaman mengajar lebih dari sepuluh tahun dan dua orang guru yang memiliki pengalaman mengajar kurang dari sepuluh tahun. Hasilnya seperti terdapat pada tabel berikut ini:

Tabel 5. Responden TPACK - Technology

\begin{tabular}{llll}
\hline No & Nama & Asal Sekolah & Pengalaman Mengajar \\
\hline 1 & RD & SMAN 2 Gunung Talang & $<10$ Tahun \\
2 & ZI & SMAN 1 IX Koto Sungai Lasi & $>10$ tahun \\
3 & YM & SMAN 1 Junjung Sirih & $<10$ Tahun \\
4 & MH & SMAN I IX Koto Sungai Lasi & $>10$ Tahun \\
\hline
\end{tabular}

Sumber : Pengolahan Data Penelitian, 2017

Untuk melihat kompetensi TPACK - Technology di kalangan guru Geografi di Kabupaten Solok maka peneliti membuat instrumen penilaian yang terdiri dari lima aspek yang dinilai dari media yang dirancang dan digunakan dalam pembelajaran yaitu:

a. Kualitas fisik media (lay out, setting, lettering, proximity, colouring and shaping, interelating, ext) b. Kualitas konten (materi dan pengembangan, akurasi dan kebaruan data/fakta, kontekstualitas).

c. Keterampilan menggunakan media

d. Keterlibatan Peserta Didik

e. Pesan dan Daya Tarik

Hasil penelitian terkait TPACK Technology di kalangan guru Geografi di Kabupaten Solok adalah: 
Tabel 6. Nilai TPACK - Technology

\begin{tabular}{lllll}
\hline No & Nama Responden & Sekolah Asal & Jumlah Nilai & Kriteria \\
\hline 1 & RD & SMAN 2 Gunung Talang & 21 & Tinggi \\
2 & ZI & SMAN 1 IX Koto Sungai Lasi & 18 & Sedang \\
3 & YM & SMAN 1 Junjung Sirih & 14 & Sedang \\
4 & MH & SMAN I IX Koto Sungai Lasi & 13 & Sedang \\
\hline
\end{tabular}

Sumber : Pengolahan Data Penelitian (2017)

Dari tabel di atas terlihat bahwa dari empat responden untuk TPACKTechnology, hanya satu responden yang memiliki kompetensi pada kriteria tinggi, sedangkan tiga lainnya berada pada kriteria sedang. Namun, dari pengamatan dan penilaian secara mendalam terungkap bahwa media pembelajaran yang ditampilkan oleh responden tidak sepenuhnya dibuat sendiri. Media tersebut didapatkan dari orang lain dan responden memodifikasi seperlunya.

Dari semua aspek penilaian pada kompetensi TPACK - Technology, aspek yang paling rendah adalah pada aspek konten/materi. Seperti terlihat pada grafik berikut ini:

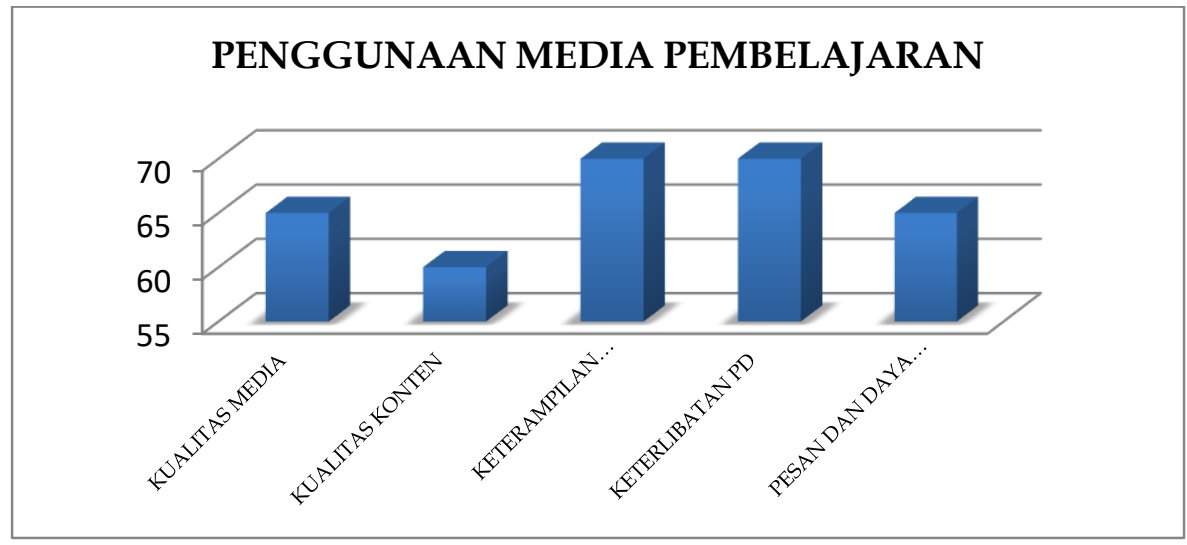

Gambar 3. Sebaran Nilai TPACK - Technology

Selanjutnya, penelitian diarahkan kepada kompetensi TPACK - Pedagogic. Untuk mendapatkan data ini, peneliti melakukan melalui analisis dokumen Rencana Pelaksanaan Pembelajaran RPP yang dibuat guru serta pelaksanaan pembelajaran melalui lembar observasi pembelajaran dan penilaian selama pembelajaran berlangsung. Untuk kompetensi TPACK - Pedagogik ini jumlah responden adalah empat orang. Hasil analisis dokumen memperlihatkan bahwa RPP yang dirancang guru relevan dengan Standar Proses dilihat dari aspek kelengkapan komponen/unsur.

Tabel 7. Relevansi RPP dengan Standar Proses

\begin{tabular}{llc}
\hline No & Responden & Relevansi Komponen/Unsur* \\
\hline 1 & RD & $100 \%$ \\
2 & ZI & $100 \%$ \\
3 & YK & $100 \%$ \\
4 & MH & $100 \%$ \\
\hline \multicolumn{2}{l}{ Sumber : Pengolahan Data Penelitian (2017) }
\end{tabular}


Namun, dalam analisis lebih lanjut terungkap bahwa RPP ini dibuat kolektif dengan mempedomani satu contoh bersama. Sehingga kalimat di RPP hampir senada.

Hasil penelitian berikutnya adalah data berupa kinerja guru dalam pelaksanaan pembelajaran. Data ini dibuat berdasarkan observasi pembelajaran guru dengan menggunakan lembar observasi pembelajaran standar PPLK/PLPG/PPG. Berikut ini merupakan data kinerja guru dalam pembelajaran:

Tabel 8. Kinerja Guru dalam Pembelajaran

\begin{tabular}{llcc}
\hline No & Responden & Hasil Observasi Pembelajaran & Tingkat Capaian \\
\hline 1 & RD & 88,09 & Tinggi \\
2 & ZI & 81,04 & Tinggi \\
3 & YK & 78,50 & Sedang \\
4 & MH & 75,56 & Sedang \\
\hline
\end{tabular}

Sumber : Pengolahan Data Penelitian (2017)

Tabel di atas memperlihatkan bahwa capaian kinerja pelaksanaan pembelajaran oleh responden menunjukkan bahwa satu responden dengan masa kerja kurang dari 10\% justru mampu menunjukkan capaian kinerja pada kriteria tinggi. Sebaliknya, satu responden dengan masa kerja lebih dari 10 tahun justru hanya menunjukkan kinerja pelaksanaan pembelajaran pada level sedang.

Berdasarkan hasil penelitian yang telah diuraikan sebelumnya maka dapat dianalisis bahwa kompetensi TPACK Guru Geografi yang tergabung dalam MGMP Geografi SMA/MA Kabupaten Solok cukup beragam. Secara umum memang tidak terlalu mengkuatirkan. Namun, karena semua responden adalah guru maka perlu diberikan penguatan dan pengkajian khusus agar guru mendapatkan bahan untuk melakukan refleksi dari hasil penelitian ini.Beberapa aspek dalam pandangan peneliti yang didasari oleh hasil penelitian dan perlu menjadi perhatian semua pihak terutama guru adalah:

1. Kompetensi TPACK - Technology
Ditinjau dari segi media presentasi yang ditampilkan guru pada saat penelitian, aspek terlemah dari enam aspek yang dinilai adalah pada pengembangan materi, disusul lay out/kualitas fisik media. Untuk mengatasi hal ini bisa dilakukan dengan memberikan pelatihan kepada guru tentang teknik menyusun materi dan mengembangkan materi pelajaran untuk disajikan dalam pembelajaran. Namun, dari pengamatan yang peneliti lakukan, sepertinya responden tidak memiliki waktu untuk merancang sendiri media presentasi pembelajaran untuk digunakan di dalam pembelajaran. Ada indikasi, responden terbiasa menggunakan media presentasi pembelajaran yang didapatkan dari suatu sumber atau yang diunduh dari internet dan hanya melakukan revisi atau penyesuaian saja. Hal ini tentu harus disadari oleh guru karena jika dalam pembelajaran menggunakan media presentasi pembelajaran yang bukan hasil karya sendiri maka guru akan mengalami kesulitan dalam menjalankannya.

\section{Kompetensi TPACK - Pedagogic}

Untuk kompetensi TPACK Pedagogic ini, secara umum tidak ada 
masalah yang mendasar. Hanya saja, dalam RPP yang disusun guru belum terlihat kreasi guru yang disesuaikan dengan kondisi ril di sekolah masingmasing. Dilihat dari aspek kesesuaian antara komponen RPP yang dibuat guru dengan komponen RPP menurut Standar Proses, semua guru sudah melakukannya dengan baik. Terkait dengan perkembangan yang ada, sepertinya sangat diperlukan pelatihan bagi guru untuk membuat RPP secara mandiri. Selain itu, guru perlu diberikan pendampingan untuk membuat RPP yang berorientasi kepada pengembangan kecakapan abad 21, 4K (creativity and innovation, critical thinking and problem solving, communication, collaboration). Serta pendampingan untuk membuat RPP yang bervisi PPK dan HOTS.

\section{Kompetensi TPACK - Content Knowledge}

Dari segi penguasaan materi mata pelajaran Geografi oleh guru terlihat bahwa guru memiliki kesulitan dalam memahami materi pada semua tingkatan kelas terutama kelas $\mathrm{X}$. Seharusnya, guruguru diharapkan mampu meraih nilai 80 untuk tes yang diberikan. Namun, hasilnya belum seperti harapan. Dari informasi yang didapatkan peneliti, penyebab masih belum tingginya tingkat penguasaan materi guru disebabkan oleh beberapa hal:

a. Guru tidak mengajar di semua tingkatan kelas sehingga pada kelas yang tidak diajar, guru memiliki penguasaan materi paling lemah.

b. Beberapa soal, dirasakan guru cukup sulit.

c. Situasi tes/ujian kurang kondusif dan guru kurang konsentrasi.

d. Soal pada materi pengetahuan dasar Geografi cukup membingungkan.

Melihat kondisi ini, maka dirasa perlu untuk memberikan pendampingan dalam rangka meningkatkan penguasaan guru terhadap materi pelajaran Geografi. Dengan penguasaan materi yang baik, guru bisa mengembangkan materi pada level yang lebih tinggi sehingga bisa menghadirkan pembelajaran yang lebih menantang. Penguasaan guru yang baik tentang materi pelajaran terutama yang berada pada level HOTS akan memicu siswa untuk terbiasa berfikir tingkat tinggi. Pembelajaran seperti ini menunjang pengembangan kecakapan abad 21. Sebaliknya, jika penguasaan materi guru rendah maka pembelajaran biasanya akan menjadi ajang hafalan semata.

Sehubungan dengan tema penelitian ini yaitu analisis kompetensi TPACK Guru Geografi yang tergabung dalam MGMP Geografi SMA/MA di Kabupaten Solok, TPACK dimaknai sebagai bentuk pengetahuan yang meliputi tiga komponen utama yaitu konten, pedagogi, dan teknologi. Pengetahuan teknologi konten pedagogis adalah pemahaman yang muncul dari interaksi antara konten, pedagogi, dan teknologi pengetahuan. TPACK adalah dasar pengajaran yang benar-benar bermakna dan sangat terampil dengan teknologi, ini berbeda dari pengetahuan tentang tiga konsep secara individual. Sebaliknya, TPACK adalah dasar dari mengajar yang efektif dengan teknologi, memerlukan pemahaman tentang representasi dari konsep-konsep yang menggunakan teknologi; teknik pedagogis yang menggunakan teknologi dalam cara yang konstruktif untuk mengajarkan materi/konten; pengetahuan tentang apa yang membuat konsepkonsep sulit atau mudah untuk belajar dan bagaimana teknologi dapat membantu memperbaiki beberapa masalah yang dihadapi siswa; pengetahuan siswa dan teori-teori Epistemologi; dan pengetahuan tentang 
bagaimana teknologi dapat digunakan untuk membangun pengetahuan untuk mengembangkan metode/cara-cara baru atau memperkuat yang lama. Namun, dalam konteks ril, pendapat Koehler \& Mishra (2008) ini perlu diurai menjadi bagian-bagian khusus sebelum mengambil keputusan secara umum. Artinya pola berfikir yang dipakai adalah pola berfikir induktif yaitu menguraikan permasalahan dari hal-hal yang spesifik menuju kepada hal-hal yang umum.

\section{KESIMPULAN}

Hasil penelitian menunjukkan bahwa TPACK - Content Knowledge Guru Geografi di Kabupaten Solok berada pada kategori sedang atau pada nilai rata-rata 51. Soal materi kelas $X$ adalah soal paling sulit bagi guru. Hasil TPACK - Technology guru Geografi menunjukkan kategori sedang. Namun, media presentasi yang ditampilkan adalah hasil modifikasi dari media yang sudah dibuat orang lain. Sedangkan TPACK - Pedagogic Guru berdasarkan kinerja dalam pelaksanaan pembelajaran memiliki rata-rata 80,79 atau berada pada kategori sedang dengan tingkat relevansi komponen RPP dengan Standar Proses adalah 100\%. Berdasarkan data di atas maka perlu diberikan pembinaan untuk meningkatkan penguasaan materi kelas $\mathrm{X}$ bagi guru. Lalu, pelatihan untuk merancang media presentasi pembelajaran berbasis Ms. Office Power Point dan lain-lain hasil karya sendiri serta penguatan dalam merancang RPP berdasarkan karakteristik siswa di sekolah masing-masing.

\section{DAFTAR PUSTAKA}

Baran, E., Chuang, Hua-Huaseh., Thomson, A. (2011). TPACK: An Emerging Research And Development Tool For Teacher Educators. TOJET: The Turkish Online Journal of
Educational Technology - October 2011, volume 10 Issue 4

Chai, C.-S., Koh, J. H.-L., \& Tsai, C.-C. (2013). A Review of Technological Pedagogical Content Knowledge. Educational Technology \& Society, 16 (2), 31-51.

Ersan, C, Y. (2016). Improving Technological Pedagogical Content Knowledge (TPACK) of Pre-Service English Language Teachers. International Education Studies; Vol. 9, No. 5; 2016. ISSN 1913-9020 E-ISSN 1913-9039. Published by Canadian Center of Science and Education

http://ukg.kemdikbud.go.id

Koehler, M. J., \& Mishra, P. (2009). What Is Technological Pedagogical Content Knowledge? Contemporary Issues in Technology and Teacher Education (CITE Journal), 9(1), 60-70

Marzano, R. J \& Heflebower, T. (2012). Teaching $\mathcal{E}$ Assssing $21^{\text {st }}$ Century Skills (The Classroom Strategies Series). E_Book from marzanoresearch.com

Mishra, P. dan M. J. Koehler. (2006). Technological Pedagogical Content Knowledge: A Framework for Teacher Knowledge. Teachers Colege Record. 6 (108): 1017-1058.

RI (Republik Indonesia). (2016). Permendikbud Nomor 22 tahun 2016 tentang Standar Proses Pembelajaran Pendidikan Dasar dan Menengah. Jakarta

RI (Republik Indonesia). (2005). Undangundang nomor 14 tahun 2005 tentang Guru dan Dosen. Jakarta

Shulman, L. S. (1986). Those who understand, knowledge growth in teaching. Educational Researcher Vol. 15, No, 2, Page 4-14.

Sugiyono. (2012). Metode Penelitian Pendidikan Pendekatan Kuantitatif, Kualitatif, dan RED. Bandung: ALFABETA. 2012 (cet. 15)

Suyanto \& Djihad, Asep. (2013). Bagaimana Menjadi Calon Guru danGuru Profesional. Yogyakarta. Multi Pressindo www.tpack.org 